\title{
Comparative Study of High-Intensity Focused Ultrasound (HIFU) Versus Laser Assisted Liposuction in Neck Tightening and Correction of Double Chin Deformity among Young Females
}

\author{
TAREK ZAHRA, M.D.; MOSTAFA ABD HALIM, M.D.; AHMED ZAYED, M.D.; TAMER ZEID, M.D. and \\ AHMED M. ZEINA, M.D.
}

The Department of Plastic and Reconstructive Surgery, Faculty of Medicine, Mansoura University, Mansoura, Egypt

\begin{abstract}
Background: High-Intensity Focused Ultrasound (HIFU) is promising for improving skin laxity with satisfactory results. However, there is no comparative study on its efficacy and safety, when compared to Laser Assisted Liposuction (LAL) which is a minimal invasive procedure.

Aim of Study: This study aimed to compare both LAL versus HIFU for neck tightening and correction of the double chin among young females.

Methodology: This prospective cross sectional study was conducted over a six months' period starting from January 2018 till July 2018, on 30 female patients for neck tightening and correction of the double chin.

Results: The clinical improvement of the skin laxity in the areas of the neck and chin after both procedures, showed excellent improvement with nearly similar results via HIFU $(60.00 \%)$ as well as LAL cases $(66.66 \%)$. The degree of the participants' satisfaction was satisfactory and nearly close among cases of both groups. Both techniques can produce satisfactory results however HIFU is considered safer, more rapid, effective, and noninvasive procedure for neck tightening, to improve the skin laxity.

Conclusion: LAL is considered suitable in selected patients, for neck and chin contouring to achieve improvement of the skin laxity and excess fat of the cervicomental zone and jowls.
\end{abstract}

Key Words: Aging neck-Double chin-High-intensity focused ultrasound - HIFU - Laser assisted liposuction - LAL - Skin laxity - Neck and face contouring - Facial tightening - Submental remodeling.

\section{INTRODUCTION}

Request for a youthful look is rising worldwide. The available techniques to the plastic surgeon range from non-invasive techniques to invasive techniques. Throughout the aging process, the skin criteria changes, with loss of elasticity due to the decrease in the number of fibroblast on the skin and the decreased synthesis of collagen and functions associated with decreased count of the skin appendages. The neck often ages more noticeably than the face [1].

The criteria of youngish look for the neck is the acute cervicomental angle and a firm, welldefined jawline with smooth healthy skin free of any neck lines; no platysmal bands; no visible submandibular glands; small, non-hypertrophic masseter muscles; and skin that is bright and even in color, with negligible melanin or vascular lesions. The aging process involves those multiple layers of the skin and soft tissue, to include the subcutaneous fat, muscle and related bony structures. The dermis thins with altered collagen and elastin functions. The ligaments and fascia that support the skin became weakened, with atrophy of subcutaneous fat and the muscles [2].

The plastic surgeon should be able to diagnose subcutaneous fat, which is preplatysmal, from subplatysmal fat, which will also compromise the acute cervicomental angle, but is more difficult to reach for management with no incisional or excisional surgery. With aging and muscle flaccidity and atrophy, the platysma bands can contribute to cervical laxity, creating a loose, adynamic, and obtuse neck [3].

The presence of excess submental fat causes a look known as a "double chin" which affects the aesthetic look of the face and neck and is a common concern among cosmetic surgery patients, regardless of sex or age. Focal accumulation of fat leading to submental convexity which is attributed to several factors mainly obesity, age-related tissue changes and genetics, which explains why younger adults and normal-weight individuals may develop a double chin [4]. The aesthetic physician needs to be able to diagnose the submental fat compartment 
"double chin", either by clinical examination or ultrasound techniques, when the submental fat is due to preplatysmal or subplatysmal pathology [5].

Suctioning of the submental and jowl regions is a low risk outpatient procedure that gives a profound aesthetic result requires a small incision in the skin for the cannula in the subcutaneous plane, or open subplatysma lipectomy. Since the late 1960s, the techniques have progressed towards a minimally invasive procedure, often combining laser-assisted therapy for enhanced skin tightening through collagen neogenesis to obtain optimal results [6].

Another procedure used for neck tightening is the ultrasound waves via inducing molecular vibration deep within the tissue, by targeting facial Superficial Muscular Aponeurotic System (SMAS) and platysmal, resulting in tissue heating deep in the dermis bypassing the epidermal layer. There are two subtypes; High Intensity Focused Ultrasound (HIFU); used in medicine and surgery, for non-surgical ablation of tumors and subcutaneous lipolysis, and Micro Focused Ultrasound (MFU) used for cosmetic purposes like skin tightening [7].

White et al., reported the first dermatologic, aesthetic use of HIFU [8], and it was approved by the Food and Drug Administration (FDA) in 2009 for use in brow lifting [9].

Right now, it is being utilized for facial rejuvenation, tightening and body contouring, which are investigated as a modern treatment for skin tightening and rejuvenation $[\mathbf{9 , 1 0}]$, as one of the recent advances in non-invasive skin tightening where it yields small, micro-thermal lesions at precise depths in the dermis up to the fibromuscular layer, causing thermally induced contraction of collagen and tissue coagulation with subsequent collagenesis, whereas saving the epidermis $[\mathbf{1 1}, \mathbf{1 2}]$.

Non-Ablative Rejuvenation (NAR) devices induce thermal injury within the dermis without epidermal damage [13] whereas, laser energy can be diffracted, absorbed, or scattered, resulting in suboptimal energy penetration [14].

Given that very few studies have been done HIFU method for neck tightening and submental fat contouring, we have conducted this study to compare HIFU versus LAL for neck tightening and correction of the double chin among young females, as regards the degree of clinical improvement, the patient's satisfaction, the adverse effects of treatment and the pain following the procedures.

\section{PATIENTS AND METHODS}

This cross sectional comparative study was conducted over a six months' period starting from January 2018 till July 2018, on 30 female patients, divided equally into two groups, aged between 20 and 45 years old, with BMI <35, non-pregnant, non-lactating. Cases complaining of redundant submental fat and moderate skin laxity of the neck and jowls were included in the study (type 1 and type 2 patients according to Baker classification [15]) where type 1 patients are those with slight cervical skin laxity with submental fat and early jowls, and type 2 patients are those with moderate cervical skin laxity, moderate jowls, and submental fat. Patients with local infections, genetic disorders of connective tissue were excluded. The study was approved by the Institutional Review Board (IRB) of the Mansoura Faculty of Medicine (R.19.02.424). Informed consent was obtained from all patients.

All patients were classified into two groups, each group contains 15 patients, where; group I: Subjected to Laser Assisted Liposuction (LAL) and group II: Subjected to High-Intensity Focused Ultrasound (HIFU). The neck was divided into 3 areas, two laterals and one medial.

\section{Procedures:}

LAL was done using a $1444 \mathrm{~nm}$ pulsed Nd:YAG lasers (Accusculpt Nd:YAG, Lutronic, Korea) using a $600 \mu \mathrm{m}$ optical fiber inserted interstitially into the fatty tissue of the target region through a $16 \mathrm{G}$ needle as the cannula to ensure correct placement of the fiber and lower the abrasive damage to the tissue at the entry point Fig. (1).

The LAL technique involved the following steps: Marking the entry points and the skin target areas, sterilization of the field of work using Chlorhexidine digluconate $0.5 \%$ in alcohol $70 \%$, Injection of local anaesthesia (Xylocaine ${ }^{\circledR} 1 \%$ with adrenaline (epinephrine 1:200,000)) at the submental and mandibular angle entry points, Ensure protection of the eye for the participating subject and the surgeon. Then a small incision is made and dilated to a diameter of $3 \mathrm{~mm}$ to create the entry point using a $16 \mathrm{G}$ needle. The procedure was performed through 3 stab incisions; one submental and one in each of the lower part of each ear lobe. A $2.5 \mathrm{~mm}$ cannula is used to infiltrate $200-300 \mathrm{ml}$ of tumescent solution $(1000 \mathrm{ml} \mathrm{NaCl} 0.9 \%$ : $1 \mathrm{mg}$ adrenaline, $12 \mathrm{ml} \mathrm{NaHCO} 38.4 \%, 1000 \mathrm{mg}$ lidocaine) across the digastric and submental regions. Use the labiomental folds for LAL at the jawline, and then make a lateral mark on the antero-lateral cervical zones of the neck on both sides. Place the needle in the subcutaneous layer and insert the 
fiber through the needle. The red beam will be visible through the skin. Move the needle and fiber forwards and backwards in the tissue in a fan-like maneuver, with the entry point as the base of the fan, and about $0.5 \mathrm{~cm}$ between each end point in the fan periphery. When the fiber reaches the periphery of the marked zone, the needle and fiber should be withdrawn for each stroke in the fan. The laser energy is emitted in a square wave (switched continuous wave) with an output power of $6 \mathrm{~W}$, pulse rate of $30 \mathrm{~Hz}$ and pulse energy of $200 \mathrm{MJ}$. A total of $60 \mathrm{~J} / \mathrm{cm}^{2}$ per treated zone should be delivered. The fiber should be moved at the constant rate of $0.3-0.5 \mathrm{~cm} / \mathrm{sec}$, be sure to keep the needle and fiber moving constantly, never remaining in the one spot for any length of time Fig. (1). A total of $1500 \mathrm{~J}$ at a setting of $6 \mathrm{~W}$ was applied across the whole treatment area. The entry holes were closed with a single suture (non-absorbable Prolene ${ }^{\circledR}$ 6-0) [6].

For group II, all patients were prohibited for 3 days from ingestion of drugs such as corticosteroids, heparin, NSAIDS. A HIFU lifting device (Doublo from Hironiccompany made by South Korea) was applied to the target regions (neck and chin). A probe of $3 \mathrm{~mm}, 4 \mathrm{~mm}, 6 \mathrm{~mm}, 9 \mathrm{~mm}$ and $13 \mathrm{~mm}$ were used, power is in the range of 0.8 to $1.5 \mathrm{MHz}$ Fig. (2). Pitch was considered 2-mm in all patients.

\section{Post-operative care:}

Group I: A neck compression garment is worn vertically and horizontally across the head is applied five days to prevent swelling and is intended to keep the soft tissue and skin in place. The average neck tite operative time was 45 minutes ( 25 minutes to 60 minutes). The average total aspirated fat volume was $30 \mathrm{~mL}(20-150 \mathrm{~mL})$. The average time for double chin contouring was 45 minutes. Group II: No specific maneuvers needed. The procedure took 30 minutes.

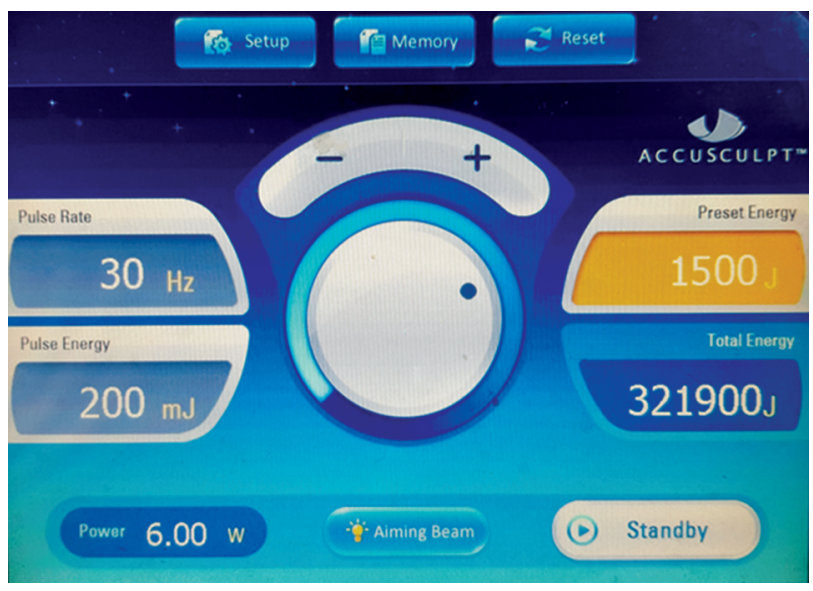

Fig. (1): Parameter of laser machine.

\section{Clinical evaluation and follow-up:}

All patients were evaluated via three independent, blinded plastic surgeons and three nurses for the clinical improvement of the skin laxity in the areas of the neck and chin by comparison of photos obtained before, and at 3 months after the procedures using a digital camera to take three views; anteroposterior and two lateral view by using the following scale: 0 , none; 1 , mild; 2 , mild/moderate; 3 , moderate; and 4, excellent clinical improvement. The overall clinical improvement was also assessed Figs. (3-5).

Also, the participants were asked to complete a Patient Satisfaction Questionnaires (PSQ) to measure the patient satisfaction and adverse effects after three months of either procedure. The questionnaire assessed the patients' satisfaction after either the HIFU or LAL techniques, their assessment of adverse effects and their opinions about whether they would like to undergo the same technique again or whether they would recommend the same experience to others. Each point of the questionnaire score were graded from 0-5, where: 1 , not satisfied; 2, somewhat satisfied; 3 , satisfied; 4 , very satisfied; and 5, extremely satisfied.

Patients also were asked to express their assessment of adverse effects, and their opinions about whether they would like to undergo further HIFU treatment or whether they would recommend LAL or HIFU to others, and their responses were recorded via YES or NO answers.

The pain following the procedures was evaluated by Visual Analogue Scale (VAS), which is a simple and reproducible tool for the assessment of pain severity consisting of 11 levels ( $0-10$ points), and was done immediately after the application of HIFU or LAL (week 0) and 3 months after.

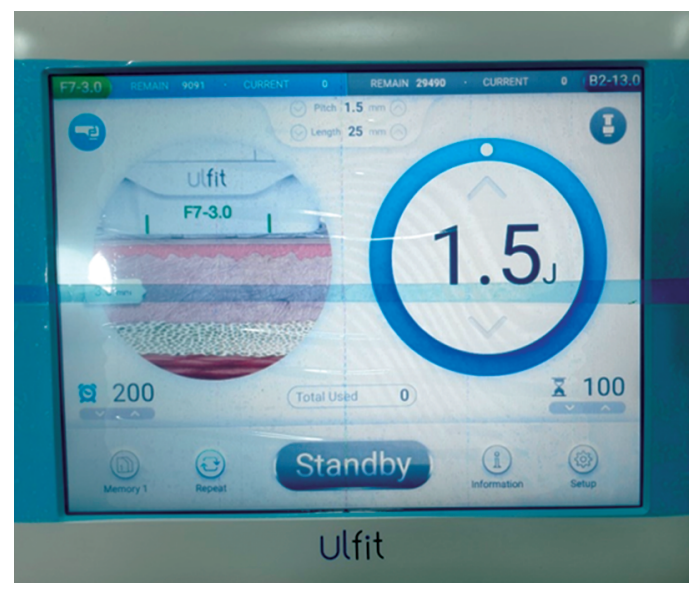

Fig. (2): Parameter of HIFU. 


\section{Statistical analysis:}

The data were analyzed using Statistical Package of Social Science (SPSS). Responses of the participants who did not supply sufficient data
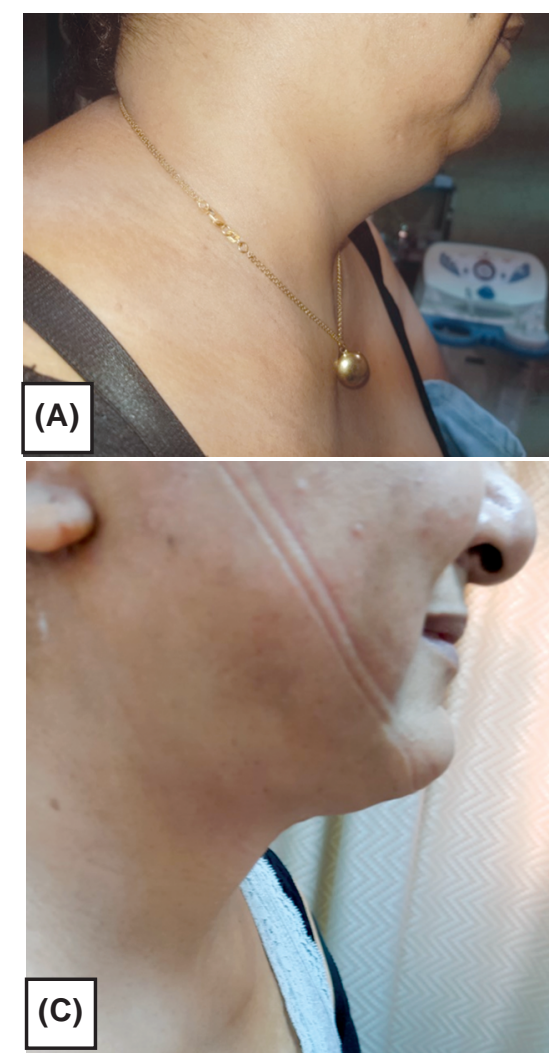

Fig. (3): (A,B) Pre-operative photos of a case with double chin deformity. (C,D) Post-operative photos after laser assissted liposuction.
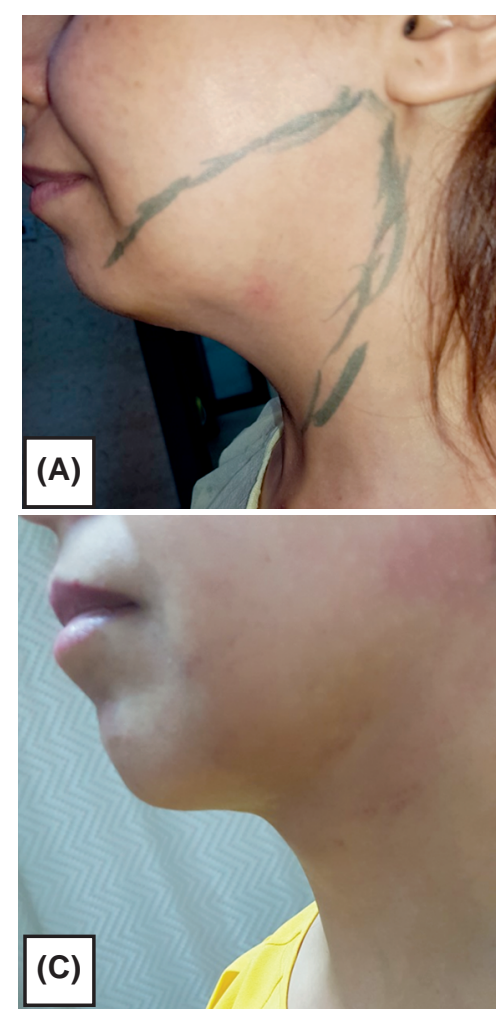

Fig. (4): (A,B) Pre-operative photos of a case with double chin deformity. (C,D) Post-operative photos after HIFU. because of not completing the questionnaires were excluded. The results were presented in the form of number and percentages. Significance was considered at $p<0.05$.
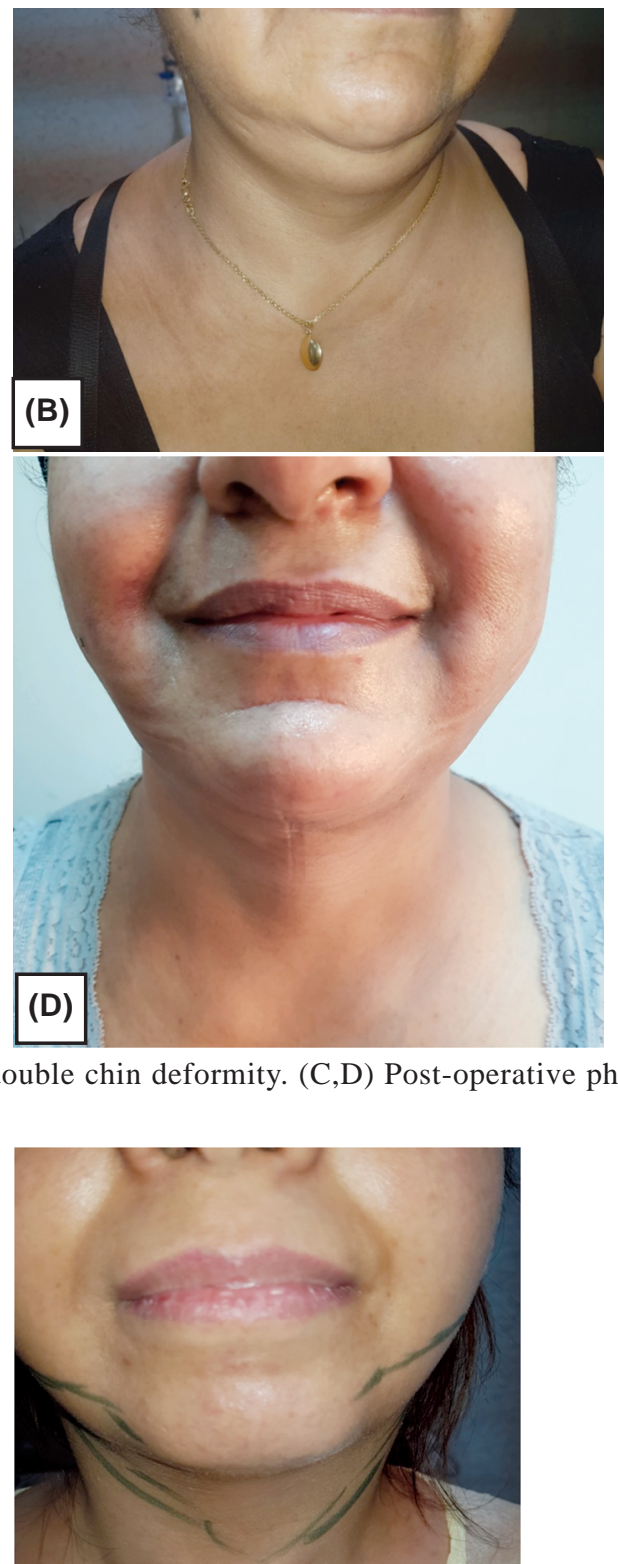

(B)

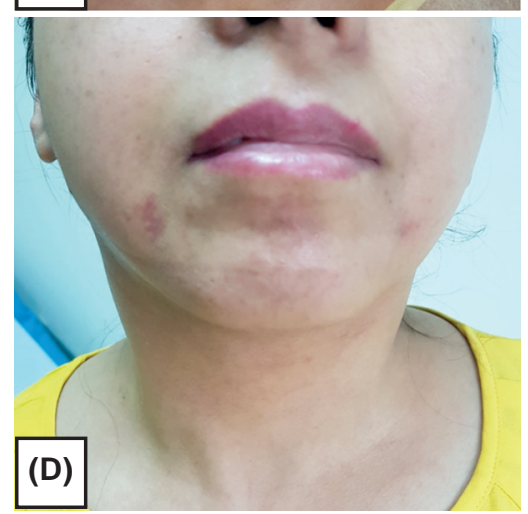

(D)

Fig. (4): (A,B) Pre-operative photos of a case with double chin deformity. (C,D) Post-operative photos after HIEU, 


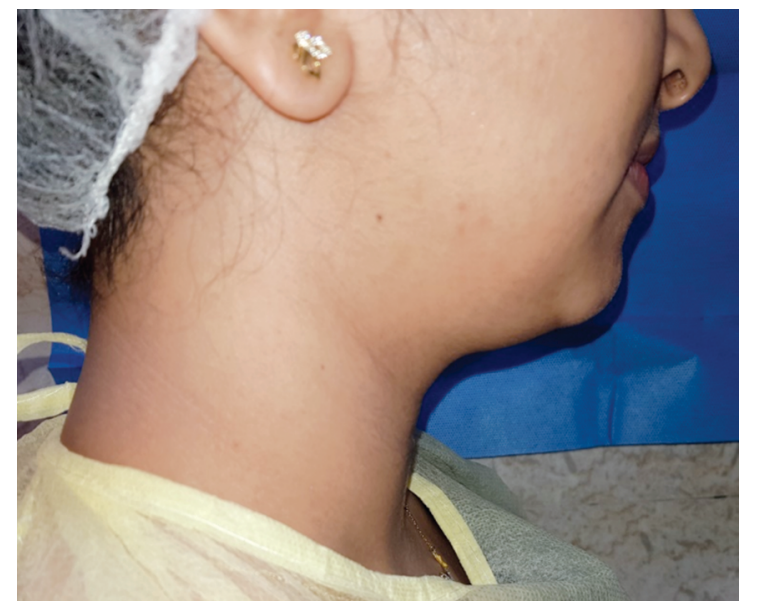

Fig. (5A): Pre-operative photos of a case with double chin deformity.

\section{RESULTS}

The age in group I $(40 \pm 5.168)$ and group II (39.53 \pm 5.3966$)$, with $\mathrm{BMI}<35,73.3 \%$ of group I and $86.666 \%$ of group II were obese, most participants were of higher education in both groups (66.66\% in group I and $86.66 \%$ of group II) and the majority of our study sample were working females $(86.66 \%$ in group I and $66.66 \%$ of group II) (Table 1). $66.66 \%$ of the participants were complaining of redundant submental fat and moderate skin laxity of the neck and jowls of type 2 according to Baker classification in group I versus $80.00 \%$ of group II.

The clinical improvement of the skin laxity in the areas of the neck and chin by comparison of standardized photographs obtained before, and at 3 months after the procedures using a digital camera, showed nearly similar results (Table 2 ) with excellent improvement via HIFU $(60.00 \%)$ as compared to LAL cases $(66.66 \%)$. The degree of the participants' satisfaction was satisfactory and nearly close among cases of both groups.

The participant's assessment of adverse effects, showed higher percentage of side effects with LAL rather than HIFU $(53.333 \%$ versus $13.333 \%$ respectively) and their opinions about whether they would like to undergo further HIFU treatment was satisfactory $80 \%$ as compared to LAL who showed only $40 \%$ who would reuse the same procedure. $46.666 \%$ of group I confirmed that they would recommend LAL to others; $93.333 \%$ of the participant of group II would recommend HIFU to others (Tables 3,4).

Immediately after the application of LAL, the mean VAS score was $6.333 \pm 0.8997$, and improved after 3 months was $4.4 \pm 0.91$. However immediately

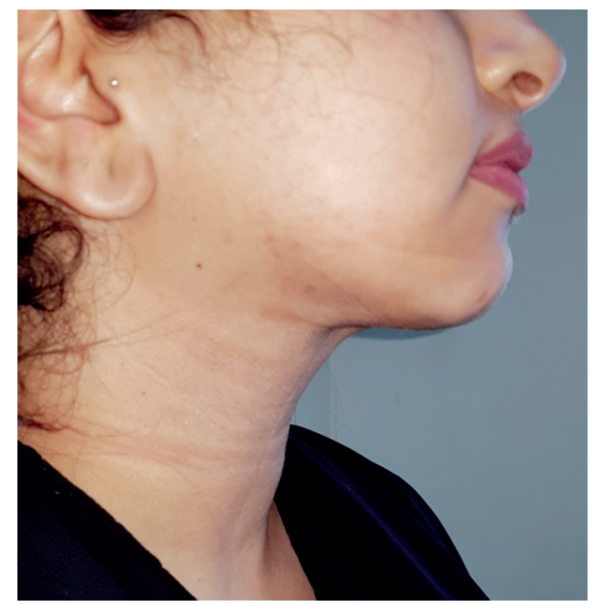

Fig. (5B): Post-operative photos after laser assissted liposuction.

after the application of HIFU the mean VAS score was $2.13 \pm 0.915$, but no pain was reported after 3 months.

Table (1): Demographic characters of the participants.

\begin{tabular}{|c|c|c|c|c|}
\hline \multirow{2}{*}{ Variables } & \multicolumn{2}{|c|}{ Group I (LAL) } & \multicolumn{2}{|c|}{ Group II (HIFU) } \\
\hline & Number & Percentage & Number & Percentage \\
\hline \multicolumn{5}{|l|}{ Age (20-45): } \\
\hline - $20-30$ & 1 & $6.666 \%$ & 1 & $6.666 \%$ \\
\hline - $31-35$ & 3 & $20.00 \%$ & 1 & $6.666 \%$ \\
\hline - $35-40$ & 4 & $26.666 \%$ & 4 & $26.666 \%$ \\
\hline - $40-45$ & 7 & $46.666 \%$ & 9 & $60.00 \%$ \\
\hline \multicolumn{5}{|l|}{$B M I(<35):$} \\
\hline - Normal (18-24.9) & 1 & $6.666 \%$ & 1 & $6.666 \%$ \\
\hline - Overweight (25-29.9) & 3 & $20.00 \%$ & 1 & $6.666 \%$ \\
\hline - Obese $(30-35)$ & 11 & $73.3 \%$ & 13 & $86.666 \%$ \\
\hline \multicolumn{5}{|l|}{$\begin{array}{l}\text { Participant's level of } \\
\text { education: }\end{array}$} \\
\hline - Primary education & 1 & $6.666 \%$ & 0 & $0.0 \%$ \\
\hline - Intermediate education & 1 & $6.666 \%$ & 1 & $6.666 \%$ \\
\hline - High school education & 3 & $20.00 \%$ & 1 & $6.666 \%$ \\
\hline - University education & 10 & $66.666 \%$ & 13 & $86.666 \%$ \\
\hline \multicolumn{5}{|l|}{ Participant's Job: } \\
\hline - House wife & 2 & $13.333 \%$ & 5 & $33.333 \%$ \\
\hline - Working & 13 & $86.666 \%$ & 10 & $66.666 \%$ \\
\hline \multicolumn{5}{|l|}{$\begin{array}{l}\text { Degree of redundant } \\
\text { submental fat and skin } \\
\text { laxity of the neck and } \\
\text { jowls according to Baker } \\
\text { classification: }\end{array}$} \\
\hline - Type 1 & 5 & $33.333 \%$ & 3 & $20.00 \%$ \\
\hline - Type 2 & 10 & $66.666 \%$ & 12 & $80.00 \%$ \\
\hline
\end{tabular}

Table (2): Clinical improvement of the skin laxity in the areas of the neck and chin.

\begin{tabular}{lcccccc}
\hline & \multicolumn{2}{c}{ Group I (LAL) } & & \multicolumn{2}{c}{ Group II (HIFU) } \\
\cline { 2 - 3 } \cline { 5 - 6 } & Number & Percentage & & Number & Percentage \\
\hline No improvement & 0 & $0.00 \%$ & & 0 & $0.00 \%$ \\
Mild & 2 & $13.333 \%$ & & 1 & $6.666 \%$ \\
Moderate & 3 & $20.00 \%$ & & 5 & $33.333 \%$ \\
Excellent & 10 & $66.666 \%$ & & 9 & $60.00 \%$ \\
\hline
\end{tabular}


Table (3): Patient satisfaction after three months via Patient Satisfaction Questionnaires (PSQ) score.

\begin{tabular}{lcccccc}
\hline & \multicolumn{2}{c}{ Group I (LAL) } & & \multicolumn{2}{c}{ Group II (HIFU) } \\
\cline { 2 - 3 } \cline { 5 - 6 } & Number & Percentage & & Number & Percentage \\
\hline 1 (Not satisfied) & 1 & $6.666 \%$ & & 0 & $0.00 \%$ \\
2 (Somewhat satisfied) & 3 & $20.00 \%$ & & 2 & $13.333 \%$ \\
3 (Satisfied) & 2 & $13.333 \%$ & & 6 & $40.00 \%$ \\
4 (Very satisfied) & 6 & $40.00 \%$ & & 5 & $33.333 \%$ \\
5 (Extremely satisfied) & 3 & $20.00 \%$ & & 2 & $13.333 \%$ \\
\hline
\end{tabular}

Table (4): Participants' opinions following either procedures.

\begin{tabular}{|c|c|c|c|c|}
\hline & \multicolumn{2}{|c|}{ Group I (LAL) } & \multicolumn{2}{|c|}{ Group II (HIFU) } \\
\hline & $\mathrm{N}$ & Percentage & $\mathrm{N}$ & Percentage \\
\hline \multicolumn{5}{|c|}{$\begin{array}{l}\text { Participant assessment of the } \\
\text { adverse effects: }\end{array}$} \\
\hline Yes & 8 & $53.333 \%$ & 2 & $13.333 \%$ \\
\hline No & 7 & $46.666 \%$ & 13 & $86.666 \%$ \\
\hline \multicolumn{5}{|c|}{$\begin{array}{l}\text { Whether they would like to } \\
\text { undergo further treatment } \\
\text { using the same procedure: }\end{array}$} \\
\hline Yes & 6 & $40.00 \%$ & 12 & $80.00 \%$ \\
\hline No & 9 & $60.00 \%$ & 3 & $20.00 \%$ \\
\hline \multicolumn{5}{|c|}{$\begin{array}{l}\text { Whether they would } \\
\text { recommend the same } \\
\text { procedure to others: }\end{array}$} \\
\hline Yes & 7 & $46.666 \%$ & 14 & $93.333 \%$ \\
\hline No & 8 & $53.333 \%$ & 1 & $6.666 \%$ \\
\hline
\end{tabular}

\section{DISCUSSION}

There is paucity of the clinical trials directed towards options for treating the aging neck. In term of skin laxity particularly, the gold standard of treatment remains rhytidectomy or facelift. In any case, there has been a sensational move towards non-surgical methods, as the patients look for to attain skin tightening with no or negligible downtime [3]. Liposuction is considered the gold standard for surgical removal of fat to manage the double chin and up to $25 \%$ of liposuction procedures target the submental region [16].

Few studies have confirmed the use of HIFU for skin tightening particularly in the area of the neck and its use for submental fat that causes the appearance of the "double chin". Therefore, this study was carried to compare between the use of the invasive technique LAL in group I versus the use of non-invasive procedure HIFU in group II, in neck lift and contouring of the double chin. The

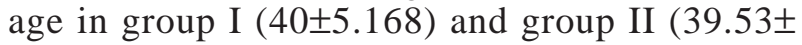
5.3966), reflecting that the willingness of the aesthetic procedures increases with increase age, particularly in late thirties and the fourth decade of age.

The neck undergoes extrinsic and intrinsic aging changes in all anatomic layers for the specialist, being talented in nonsurgical cervical rejuvenation is critical, as many patients may need for nonexcisional cervical enhancements, alone, or in combination with other facial restorative surgical strategies.

Several studies confirmed the same results as the current study, increasing the BMI leads to a relative broadening of the midface and lower face and that individuals with lower body fat proportion have a more angular face with moderately narrower cheeks and a pointed chin [17-19].

In our study, the clinical improvement showed excellent improvement of the skin laxity in the areas of the neck and chin after three months for both procedures, with nearly similar results via HIFU $(60.00 \%)$ as well as LAL cases $(66.66 \%)$. Evidence based studies confirmed the efficacy of HIFU skin-tightening devices [20].

Suh et al., in their studies reported that HIFU was a safe and effective modality for skin tightening of the [12]. Park et al., unlike all previous studies, evaluated each part of face after HIFU treatment, they detailed that the clinical effects of HIFU were similar in all areas, where improvement was prominent after 3 months and showed a gradual decrease with time [20]. Studies reported that HIFU showed the highest level of neocollagenesis and neoelastogenesis in the reticular dermis [21].

Laser lipolysis and ultrasound-assisted liposuction treat fat in a manner different from conventional liposuction; where fat is removed via cavitation, via the implosion of adipose cells followed by lysis and emulsification [22]. It helps remove those areas of redundant and prolapsed fat whereas countering skin laxity, and address both jowl formation and submental flaccidity via stimulation of neocollagenesis in the dermal layer overlying the fatty layer being treated through secondary photothermal effect, enhancing the elasticity of the skin and facilitating the skin contraction in the operative region, yet with mild trauma [23]. This goes with the excellency of our results in group one who used LAL.

Jianu et al., in their results showed a significant improvement in the fat distribution, the skin condition and the contour correction in all the patients treated with LAL, which was noticeable at 10 days' post-treatment [23].

LAL with liposuction has a statistically significant effect on skin shrinkage and tightening of the skin in the abdominal area when compared to liposuction alone [24]. Therefore, all evidence based 
studies confirmed the role of laser lipolysis to liquefy the adipose tissue and stimulate neocollagensis, yet more results are needed to assure its role in neck tightening and double chin.

The degree of the participants' satisfaction after three months was satisfactory and nearly close among cases of both groups (13.33-40.00\%) in group I and II were of variable degree of satisfaction, only $6.66 \%$ were not satisfied with the results in group I. Senra reported high satisfaction with laser lipolysis (93.2\%) [22].

The participant's assessment of adverse effects, showed higher percentage of side effects with LAL rather than HIFU $(53.33 \%$ versus $13.33 \%$ respectively) and their opinions about whether they would like to undergo further HIFU treatment was satisfactory $80 \%$ as compared to LAL who showed only $40 \%$ who would reuse the same procedure. Only $46.66 \%$ of group I confirmed that they would recommend LAL to others as compared to $93.33 \%$ of the participant of group II would recommend HIFU to others.

The results obtained with laser lipolysis when used as an adjuvant to conventional liposuction, has proved to improve the patient recovery, particularly for contouring the irregularities after liposuction treatment [22].

Ko et al., evaluated the viability and safety of HIFU in skin lifting and demonstrated that the unfavorable impacts were restricted to transient pain in most patients and occasional erythema or ecchymosis in some patients. Also, Nayak in his study to evaluate the efficacy of HIFU for neck lifting detailed no pain at 4 and 12 weeks posttreatment and no serious side effects during the follow-up [25].

One of the limitation of our study, is the small sample size, and the relatively short follow-up period of less than 6-months with inclusion of only young female patients which hinders the generalization of our results and in evaluating the degree of satisfaction from the procedure we only applied it to the patient not to the aesthetic surgeon too.

One of the main strengths of this study, is that it is the first study, to best of our knowledge, to assess both LAL and HIFU in the skin tightening in that region (the neck) and eliminating fat in the submental region with either a minimally invasive surgical procedure (LAL) or (HIFU), a totally noninvasive procedure and compare both techniques and assess the satisfaction with the results posttreatment.
Based on our results, we recommend a Handson-training preceptorship then beginning with larger body cases and to start working in the neck and face with conservative parameters and further studies to generalize the use of HIFU in neck lifting and chin contouring.

\section{Conclusions:}

Finally, we conclude that LAL though a very promising treatment for these areas and a good alternative to open, excisional surgery, with longlasting results in selected patients. Whereas, HIFU is considered safer, more rapid, effective, and noninvasive procedure for neck tightening, to improve the skin laxity and is particularly effective in improving the skin tone, facial contour and lesser incidence of subjective symptoms such as tightness or tension on the skin, and no postoperative edema, bruises or need to wear corset.

\section{Conflict of interest:}

The author declared no conflict of interest.

\section{REFERENCES}

1- Zandvakili H., Hamid H.R. and Chabok R.: Patient satisfaction and efficacy of accent high-intensity focused ultrasound for face lifting. International Journal of Advanced Computer Research; Vol. 6 (26): 2249-7277, 2016.

2- Mulholland R.S.: Non excisional, Minimally Invasive Rejuvenation of the Neck. Clin. Plastic Surg., 41: 11-31, 2014.

3- Lahham S.A., Mokhallalati A.M., Sada R., Badran S., Zahid R., et al.: Non-Surgical Neck Contouring. Cosmetol. J., 2 (2): 000111, 2018.

4- Rzany B., Griffiths T., Walker P., et al.: Reduction of unwanted submental fat with ATX-101 (deoxycholic acid), an adipocytolytic injectable treatment: Results from a phase III, randomized, placebo-controlled study. Br. J. Dermatol., 170 (2): 445-53, 2014.

5- Shamban A.T.: Noninvasive Submental Fat Compartment Treatment. Plast. Reconstr. Surg. Glob. Open, 4 (12) Suppl Anatomy and Safety in Cosmetic Medicine: Cosmetic Bootcamp): e1155, 2014.

6- Fouché J.J.: Laser-assisted submental liposuction. PMFA Journal; Vol. 5 (3), 2018.

7- Fabi S.G.: Noninvasive skin tightening: Focus on new ultrasound techniques. Clin. Cosmet. Investig. Dermatol., 8: 47-52, 2015.

8- White W.M., Makin I.R., Barthe P.G., Slayton M.H. and Gliklich R.E.: Selective creation of thermal injury zones in the superficial musculoaponeurotic system using intense ultrasound therapy: A new target for noninvasive facial rejuvenation. Archives of Facial Plastic Surgery, 9 (1): 22-9, 2007.

9- Lee H.J., Lee K.R., Park J.Y., Yoon M.S. and Lee S.E.: The efficacy and safety of intense focused ultrasound in the treatment of enlarged facial pores in Asian skin. Journal of Dermatological Treatment, 26 (1): 73-7, 2015. 
10- Brobst R.W., Ferguson M. and Perkins S.W.: Ulthera: Initial and six month results. Facial Plastic Surgery Clinics of North America, 20 (2): 163-76, 2012.

11- Gliklich R.E., White W.M., Slayton M.H., Barthe P.G. and Makin I.R.: Clinical pilot study of intense ultrasound therapy to deep dermal facial skin and subcutaneous tissues. Archives of Facial Plastic Surgery, 9 (2): 88-9, 2007.

12- Suh D.H., Shin M.K., Lee S.J., Rho J.H., Lee M.H., et al.: Intense focused ultrasound tightening in Asian skin: Clinical and pathologic results. Dermatol. Surg., 37 (11): 1595-602, 2011.

13- Wanitphakdeedecha R., Ungaksornpairote C., Kaewkes A., Rojanavanich V., Phothong W., et al.: The comparison between intradermal injection of abobotulinumtoxinA and normal saline for face lifting: A split face randomized controlled trial. J. Cosmet. Dermatol., 15 (4): 452-7, 2016.

14- Montes J.R., Wilson A.J., Chang B.L. and Percec I.: Technical Considerations for Filler and Neuromodulator Refinements. Plast. Reconstr. Surg. Glob. Open, 4 (12): e1178, 2016.

15- Baker D.C.: Lateral SMASectomy, plication and short scar facelifts: Indications and techniques. Clin. Plast. Surg., 35: 533-50, 2008.

16- Perry A.W.: Submental and jowl liposuction. Accessed January 14, 2015. Available at: http://emedicine.medscape. com/article/1272432-overview\#a0199, 2015.

17- Ferrario V.F., Dellavia C., Tartaglia G.M., Turci M. and Sforza C.: Soft tissue facial morphology in obese adoles- cents: A three-dimensional noninvasive assessment. Angle Orthod., 74 (1): 37-42, 2004.

18- Coetzee V., Chen J., Perrett D.I. and Stephen I.D.: Deciphering faces: Quantifiable visual cues to weight. Perception, 39 (1): 51-61, 2010.

19- Lee B.J., Do J.H. and Kim J.Y.: A classification method of normal and overweight females based on facial features for automated medical applications. J. Biomed. Biotechnol., 2012: 834578 10, 2012.

20- Park H., Kim E., Kim J., Ro Y. and Ko J.: High-Intensity Focused Ultrasound for the Treatment of Wrinkles and Skin Laxity in Seven Different Facial Areas. Ann. Dermatol., 27 (6): 688-93, 2015.

21- Chan N.P., Shek S.Y., Yu C.S., Ho S.G., Yeung C.K. and Chan H.H.: Safety study of transcutaneous focused ultrasound for non-invasive skin tightening in Asians. Lasers in Surgery and Medicine, 43 (5): 366-75, 2011.

22- Senra A.B.: Evaluation of laser lipolysis: 10 years of experience with 766 patients, 28 (3): 389-97, 2013.

23- Jianu D.M., Filipescu M., Jianu S.A., Nita A.C. and Chirita D.A.: The sinergy between lasers and adipose surgery in face and neck rejuvenation: A new approach from personal experience. Laser Ther., 21 (3): 215-22, 2012.

24- Di Bernardo B.E. and Reyes J.: Evaluation of skin tightening after laser-assisted liposuction. Aesthet. Surg. J., 29 (5): 400-7, 2009.

25- Ko E.J., Hong H., Kwon T.R., Choi E.J., Jang Y.J., et al.: Efficacy and Safety of Non-invasive Body Tightening with High Intensity Focused Ultrasound (HIFU). Skin. Res. Technol., 23 (4): 558-62, 2017. 